\title{
Raising Our Sites: Dissemination of Supported Education
}

\author{
Carol T. Mowbray, PhD \\ Chyrell D. Bellamy, MSW \\ Deborah Megivern, PhD \\ Steve Szilvagyi, MA
}

\begin{abstract}
In order to promote replication of supported education, an exemplary rehabilitation model for adults with psychiatric disabilities, funds were accessed through a Community Action Grant from the Center for Mental Health Services of the Substance Abuse and Mental Health Services Administration. Three communities in Michigan participated in a multistage process designed to maximize community ownership by encouraging local adaptations involving all stakeholder groups and providing technical assistance. The stages in the process were organizing the community for supported education development, acquiring knowledge about supported education basics, collecting information (needs assessment and barrier identification), and developing the plan. All three sites have begun implementation, providing services to adults with psychiatric disabilities who wish to pursue post-secondary education. The approach employed has applicability for other local communities.
\end{abstract}

\section{Introduction}

Psychiatric rehabilitation services have increased in number and visibility in the last 20 years. The focus on psychiatric rehabilitation services has resulted, in part, from altered conceptualizations of mental illness as a disability requiring long-term, restrictive treatment; newer medical treatments for psychiatric disorders (improved diagnosis and medications); demonstrated efficacy of rehabilitative interventions; and the realization that recovery and community integration are possible. ${ }^{1}$ Despite greater interest in psychiatric rehabilitation services, mental health systems have limited ability to initiate new programs for various reasons-cutbacks in human services funding, public distrust of government-operated services, increased use of managed behavioral health care, and the majority of savings accruing from downsizing of institutions have already occurred. In the past, increased funding has spurred major changes in mental health services (eg, availability of disability income for people with mental illnesses living in the community, federal Medicaid funding for mental health under Rehabilitation and Clinic Services Options). Since the current likelihood of increased revenues seems remote, other strategies are needed for program development.

This article describes efforts to replicate a psychiatric rehabilitation technology-supported education-an effective and expanding program model for adults with psychiatric disabilities. The

Address correspondence to Carol T. Mowbray, PhD, Professor and Associate Dean for Research, School of Social Work, University of Michigan, 1080 South University, Ann Arbor, MI 48109-1106; e-mail: cmowbray@umich.edu.

Chyrell D. Bellamy, MSW, is Graduate Student Research Assistant, School of Social Work, University of Michigan.

Deborah Megivern, $\mathrm{PhD}$, is Research Associate, George Warren Brown School of Social Work, Washington University, St. Louis.

Steve Szilvagyi, MA, is SE-CAG Project Director, School of Social Work, University of Michigan.

Joumal of Behavioral Health Services \& Research, 2001, 28(4), 484-491, @ 2001 National Council for Community Behavioral Healthcare. 
initiation of new programs using this supported education technology was facilitated with only the following: (1) federal funding to pay for technical assistance, (2) existing local resources and interests, (3) prior experiences with and documentation of the effectiveness of supported education, and (4) community organizing techniques. The approach described resulted in increased availability of supported education services in three Michigan communities to provide the assistance and supports consumers need to succeed in post-secondary educational pursuits. The current article describes how this project "raised these sites" through community organizing and replication/dissemination strategies. In so doing, the "sights" and hopes of local constituency groups were also raised.

\section{Background on Supported Education}

Supported education (SEd) for individuals with psychiatric disabilities arose in the last decade in response to increased workplace demands for education and skills, shortcomings of vocational programming, and stated desires of consumers and family members., ${ }^{2,3}$ The first supported education program started as a federally funded demonstration project at Boston University's Center for Psychiatric Rehabilitation in the 1980s. Supported education is based on psychosocial rehabilitation principles and provides assistance, preparation, and ongoing support to adults with psychiatric disabilities who wish to pursue post-secondary education or training. Participants in SEd programs increase their knowledge and skills in numerous college-related topics ranging from how to manage psychiatric symptoms and medications to how to negotiate campus life. While SEd does not give college credits directly, it does offer immersion in the normalizing environment of a college campus, access to recreational and cultural resources, methods to strengthen basic educational competencies, opportunities for career planning, professional support for navigating academic environments, and peer support from SEd students and staff. ${ }^{3}$ Successful outcomes from completing a supported education program could be enrollment in a community college, university, technical training, or other vocational program, or a decision to begin career development directly by obtaining employment in a chosen area.

Reviews of publications or professional presentations have resulted in identification of more than 20 SEd programs across North America, each using a different format (group or individual), duration, and setting (typically suburban and urban communities). ${ }^{4}$ Unfortunately, these SEd programs are primarily concentrated in six states, leaving the majority of the United States with either a single program or no supported education services whatsoever. Nonetheless, although supported education is a recent innovation, evidence of its effectiveness is accumulating. ${ }^{5,6}$ The Michigan Supported Education Program (MSEP) began in Detroit as a research/demonstration project funded through the Center for Mental Health Services of the Substance Abuse and Mental Health Services Administration (CMHS/SAMHSA) and utilized a true experimental design to test the effectiveness of this model. MSEP also was unique in serving a large number of participants annually and in recruiting from the public mental health system in an urban area. Evaluations of MSEP and other supported education programs have shown significant increases in college enrollment and competitive employment following receipt of SEd services, as well as improvements in self-perceptions. ${ }^{6-9}$ Documentation of SEd effectiveness and replicability led to its endorsement as an exemplary service model by the CMHS/SAMHSA, and receipt of federal funding for replication/dissemination through a community action grant.

\section{Replication Strategy}

The goal of the supported education community action grant (SE-CAG) was to facilitate the development of three new, fully functioning SEd programs in Michigan, serving diverse populations in varying locations. The planning approach was intended to encourage adaptations of the SEd 
model based on community needs, to enhance investment of resources from all interested parties, and to maximize local support. ${ }^{10}$ Following community organizing principles, ${ }^{11}$ the project engaged the sites in the following activities: obtaining knowledge of the desired change and how it could be achieved, collecting information concerning local needs and resources, acquiring skills and accessing resources necessary to utilize the knowledge and information available, identifying individuals who could serve as role models to intended beneficiaries, and problem solving to overcome barriers to implementation.

The key steps to the desired systems change were as follows:

- organizing community stakeholders and engaging them in a planning process

- educating stakeholders on supported education choices in the context of community resources

- conducting comprehensive educational needs assessments of potential participants

- identifying barriers created by mental illness, mental health systems, vocational rehabilitation, educational sites, lack of resources, and managed behavioral health care

- providing technical assistance for overcoming barriers

- formulating values and plans for supported education in each community

For the SE-CAG project, the foregoing steps were formulated into four distinct stages of development (see Table 1). Stage I involved organizing and engaging key stakeholders, while stage II focused on education in the context of identified community resources. In stage III, sites completed assessments of educational needs and barriers to their attainment and, in stage IV, sites were offered technical assistance to overcome the barriers and encouraged to formulate their own, locally responsive, SEd plan. Detailed activities associated with each stage are described below.

\section{Stakeholder management}

SE-CAG stage I began by organizing an SEd planning process at state and local levels, involving five stakeholder groups: consumers, family members, higher education, vocational rehabilitation, and mental health services. Experience and published articles suggest that lack of involvement of these key stakeholders can create significant barriers to SEd implementation. ${ }^{3}$ A state-level advisory group of representatives from these five groups was organized, and the group provided input on the SE-CAG proposal before the grant was submitted. This action served to begin stakeholder investment at the earliest possible point and to legitimize involvement of local stakeholders since their statelevel counterparts were represented. Once funding was received, the advisory group developed a request for proposals. This process was designed to stimulate interest by initiating a somewhat competitive process. Staff employed many promotional techniques: a contact/mailing list to all interested stakeholders from potential local sites, press releases and announcements in relevant newsletters to educate constituents and further engage their interests, and a SE-CAG brochure to publicize SEd.

Seven community agencies (clubhouses and community mental health boards) submitted applications to receive assistance on developing an SEd program. Due to restrictions on travel time availability and costs, the number of sites had to be limited. Criteria for site selection were: demonstrating SEd principles, involving stakeholder groups, having a strong agency commitment, and addressing multicultural issues. The advisory group chose five sites, rejecting two because applicants had not demonstrated any coordination with the other stakeholders.

\section{Education}

In stage II, SE-CAG offered the five sites an all-day workshop to educate stakeholders about SEd and the ways it has been implemented within differing resource environments. A recognized national expert detailed the goals and operation of supported education. The most persuasive communications 


\section{Table 1}

Stages of development for supported education programs

\begin{tabular}{|c|c|c|c|}
\hline Stage & Focus & Action steps & Lessons learned \\
\hline I & $\begin{array}{l}\text { Organizing and } \\
\text { engaging } \\
\text { stakeholders }\end{array}$ & $\begin{array}{l}\text { Establish state-level advisory } \\
\text { committee. } \\
\text { Devise promotional methods to } \\
\text { motivate local communities to } \\
\text { get involved. } \\
\text { Make initial contacts with/gain } \\
\text { involvement of stakeholder } \\
\text { groups. }\end{array}$ & $\begin{array}{l}\text { A lot of promotion is needed to } \\
\text { motivate participation. } \\
\text { Some competition among } \\
\text { prospective sites works well. } \\
\text { Sites are very heterogeneous in } \\
\text { terms of various stakeholder } \\
\text { attitudes. } \\
\text { Many locations have no history } \\
\text { of working collaboratively } \\
\text { with vocational rehabilitation } \\
\text { or higher education. }\end{array}$ \\
\hline II & $\begin{array}{l}\text { Education in the } \\
\text { context of } \\
\text { community } \\
\text { resources }\end{array}$ & $\begin{array}{l}\text { Have local planning group } \\
\text { members come together. } \\
\text { Orient on supported education } \\
\text { principles and values plus } \\
\text { provide overviews of model } \\
\text { adaptations from other locations. } \\
\text { Have stakeholders complete } \\
\text { resource assessments. }\end{array}$ & $\begin{array}{l}\text { Important to identify lead } \\
\text { agency up front. Teaching } \\
\text { about supported education } \\
\text { most credible if it combines } \\
\text { outside expert with } \\
\text { presentations from consumers } \\
\text { who attended supported } \\
\text { education. } \\
\text { Resource assessments usually } \\
\text { provided information on } \\
\text { unknown resources. }\end{array}$ \\
\hline III & $\begin{array}{l}\text { Needs and barriers } \\
\text { assessments }\end{array}$ & $\begin{array}{l}\text { Plan for needs assessment (NA) of } \\
\text { potential supported education } \\
\text { participants. } \\
\text { Involve consumers in conducting } \\
\text { needs assessments. } \\
\text { Conduct barrier identification } \\
\text { using needs assessment results. }\end{array}$ & $\begin{array}{l}\text { Having some funds to } \\
\text { compensate consumers } \\
\text { increases involvement. } \\
\text { To make NA data really useful } \\
\text { requires technical assistance } \\
\text { in compiling results. } \\
\text { Many barriers are internal to } \\
\text { participants and/or agency } \\
\text { staff. }\end{array}$ \\
\hline IV & $\begin{array}{l}\text { Producing a plan for } \\
\text { implementing } \\
\text { supported education } \\
\text { locally }\end{array}$ & $\begin{array}{l}\text { Involve all stakeholders. } \\
\text { Use needs and resource } \\
\text { assessments and barrier } \\
\text { information. } \\
\text { Plan implementation in stages. }\end{array}$ & $\begin{array}{l}\text { Needs assessment results and } \\
\text { initial participation do not } \\
\text { predict outcomes. } \\
\text { Lead agency needs to be pushed } \\
\text { to continue stakeholder } \\
\text { involvement. } \\
\text { Generally, those stakeholders } \\
\text { highly involved in planning } \\
\text { maintained their } \\
\text { commitments. }\end{array}$ \\
\hline
\end{tabular}


were testimonials from graduates of Detroit's MSEP. Assessing community resources for SEd also was covered (who to engage in the process, how and what information to collect, and how to organize materials). The five local sites then selected their host agency. This was necessary to ensure that each site had an entity responsible for arranging subsequent meetings, planning resource assessments, and further developing the SEd coalition. SE-CAG encouraged sites to identify and engage local consumers pursuing higher education in order to cultivate leadership.

Producing a resource assessment was a task to be shared by all stakeholders involved in the local planning groups. For the most part, sites were surprised at the availability of relevant resources in their communities. Advisory group reviews of resource assessments submitted from each local site indicated that two levels of continued SE-CAG support were appropriate: (1) providing monetary and staff support in order to conduct needs assessments (at three sites) and (2) providing replication information with limited consultation (at two sites). The latter sites had less meaningful involvement from key stakeholders, particularly vocational rehabilitation.

The three sites chosen for full SE-CAG support can be described as follows:

- Community A was one of the largest urban areas in the state, predominantly an African American, working class population, but including a major state university.

- Community B was a suburban area with a mid-sized city, predominantly a Caucasian, middleclass population, but including a major state university.

- Community $\mathbf{C}$ was a mixed urban and suburban area, but less populated than Community $\mathrm{A}$. The population was primarily a Caucasian one, but more diverse than Community B, with representation of African American, Southeast Asian, and Mexican American populations; it was predominantly middle and working class and included a large state university in a neighboring city.

\section{Assessments}

For stage III of SE-CAG, the planning groups from the three chosen sites worked closely with project staff on needs assessments and on identification and resolution of barriers. A second workshop was held, combining representatives from all three sites. The focus was on needs assessment. A handbook was distributed that described methods for collecting information from consumers, providers, and referral sources. It built on the resource assessments previously conducted and outlined advantages and disadvantages of each method. The benefits of meaningful consumer involvement throughout the needs assessment process were emphasized. Each site was given funding to offset the local costs of conducting the needs assessment and was assigned a field consultant to provide technical assistance.

The needs assessments were completed about 3 months later. Each site's needs assessment did include active participation from many stakeholders, with consumers in primary roles-leading focus groups, developing survey instruments, and conducting interviews. The needs assessment at each site included the following:

- Community A-46 interviews and 2 consumer focus groups

- Community B-29 surveys from consumers, 8 surveys from non-consumers, and 5 focus groups with consumer organizations

- Community C-52 surveys (one set from current and prospective students, the other from agency staff)

Several sites asked for help so that they could accurately summarize the data collected. At one site, a SE-CAG research assistant entered and analyzed data and prepared tables and other summary statistics. 
Needs assessment results were used to identify barriers. Surprisingly, identified barriers included the attitudes of potential participants (fear, reluctance, ambivalence) and of mental health agency staff (consumers are not capable; education is too stressful).

\section{Implementation plan}

Stage IV focused on technical assistance from SE-CAG staff and consultants to provide information or strategies to help each site access available resources and overcome the identified barriers. Each host agency, along with local stakeholders, developed an implementation plan after discussing strategies for addressing the barriers. The resource and needs assessments served as major tools for planning. Plans were reviewed by SE-CAG for their completeness, responsiveness to participant needs, adaptation to local conditions, feasibility in light of identified barriers, and inclusiveness. Feedback to each site focused on resolution of identified weaknesses and recommended improvements to ensure successful SEd implementation.

\section{Results}

The sites chose to implement locally eclectic approaches to SEd, combining elements of individual, group support, and curriculum-based models. In each plan, the SEd site was to provide career exploration, tutoring, individual and group support, educational resources, skill building for academic survival, and stress/time management. All sites sought to obtain program space from their local college and planned to provide access to educational resource centers including computers for consumers. Plans also included utilizing tutoring services identified in community resource assessments.

SE-CAG was funded to continue providing technical assistance to sites for a second implementation year. A statewide SEd coalition has been established that, hopefully, will become self-sustaining and provide each site with ongoing support, problem-solving help, and technical assistance.

There are now three new sites for SEd in Michigan, along with two others developing SEd on their own, thanks to the community action grant and the motivation of consumers and other supporters to pursue higher education in PSR. As with other sites providing SEd services, these supported education programs should offer the road to rehabilitation and recovery for many consumers who might otherwise atrophy or destabilize in mental health and vocational programs or fail to find meaningful employment due to the lack of higher education and training.

For the future, SE-CAG will continue to support the developing Michigan sites. In addition, funding has been received from the US Department of Education, Fund for the Improvement of PostSecondary Education, to begin technical assistance for replication and dissemination to four states in the Midwest. The experiences in Michigan indicate that supported education is a beneficial model for adults with psychiatric disabilities and that the community action strategy is a useful approach to promote replications of other model programs in local sites.

\section{Limitations}

The planning process described would probably work in many different locations for many different program initiatives, with some noteworthy exceptions. Use in an extremely rural area is likely to be a problem because agency representatives, advocates, and consumers would have to travel long distances to meet. Furthermore, it could be that all five stakeholder groups simply would not be represented in some sparsely populated rural areas (ie, the vocational rehabilitation agency and the mental health services program might be in two different towns or there might not be a consumer or family member group in that county). In terms of diverse program initiatives, planning based on 
consumers expressing their needs to other consumers probably would not work where the needs involve less accepted behaviors (like drinking or drug use) or where the social problems dealt with are controversial (such as adoption, abortion, housing). However, with these kinds of exclusions, the SE-CAG stages of development approach would seem to have promise in that behavioral health care funders are increasingly calling for funding of only models proven to be effective. However, in most instances, even the most successful model will not operate in another location without some adaptation. The SE-CAG approach requires local programs to consider needed adaptations; it also maximizes the likelihood of local ownership and collaboration to share available and previously unknown resources.

\section{Implications for Behavioral Health Services}

All in all, the SE-CAG community change model worked quite well. However, as presented in Table 1, there were some unexpected results. First, it had been expected that the volume of promotional activity (eg, letter writing to more than 200 agencies) would produce more than the seven responses received. It also was surprising that there was little contact or interaction between mental health agencies or advocacy groups and either higher education institutions or vocational rehabilitation offices in many communities. More initiatives to bring these agencies and organizations together are needed.

Second, the activities conducted in stage II seemed to work particularly well. Going to each site with SEd presenters was definitely advantageous in that it allowed involvement from locally based individuals, many of whom would not have traveled to a centrally located site. For example, one site had substantial attendance from the disability community. In all sites but one, this "show-and-tell" approach brought out large crowds and enthusiastic participation. Also, the strategy of having each local stakeholder collect information for a part of the resource assessment was an ideal strategy. It usually solidified an individual's involvement by giving him or her something to do; further, the individual's task involved his or her unique knowledge base and connections, was concrete, and often produced a positive result.

In stage III, having consumers participate in planning and collecting data for the needs assessments also worked well. It seemed to provide more of an entry into the population group to be surveyed, increased the visibility of supported education, and provided consumers with extra cash. While there were some benefits from just doing the needs assessment, the overall outcome for SEd services seemed more successful when the site also took the time and effort to review the data collected thoroughly and use them specifically to identify barriers and suggest some feasible ways to overcome them. For example, finding out that some barriers arose from attitudes of consumers and mental health staff provided important information that program planners could draw on when recruitment was more difficult than expected.

In stage IV, once the plan was completed, many of the stakeholders (sometimes even consumer groups and family/advocacy organizations) dropped out of the process. However, those stakeholders who were very active continued to be involved. It had been assumed that once engaged, stakeholders would maintain involvement. Obviously, longer term, and perhaps more intensive pushes and incentives, are needed. The SE-CAG project definitely underestimated how unusual it is and how infrequently coordinated activity of this set of multiple stakeholders occurs in a community. Unfortunately, in many instances collaboration is preceded by a crisis event, rather than by proactive planning.

Finally, having a combination of "inside" and "outside" people seems to have very positive effects. For example, the SE-CAG orientation included an out-of-state expert for credibility plus consumers who had participated in an SEd program within Michigan State. As another example, the production of the various assessments and plans were produced by the local planning groups, but then critiqued by the state advisory council, with feedback provided. 


\section{Acknowledgment}

This work was funded by grant KD1-SM52684 from the Center for Mental Health Services, Substance Abuse and Mental Health Services Administration, to the University of Michigan, School of Social Work.

\section{References}

1. Anthony WA. Recovery from mental illness: a guiding vision of the mental health system in the 1990s. In: Spaniol L, Brown MA, Blankertz L, et al, eds. Introduction to Psychiatric Rehabilitation. Columbia, MD: IAPSRS; 1994:557-567.

2. Rogers ES, Anthony W, Toole J, et al. Vocational outcomes following psychosocial rehabilitation: a longitudinal study. Journal of Vocational Rehabilitation. 1991;1:21-29,

3. Moxley D, Mowbray C, Brown K. Supported education. In: Flexer R, Solomon P, eds. Psychiatric Rehabilitation in Practice. New York: Butterworth Press; 1993:137-153.

4. Megivem D, Holter MC. The involvement of vocational rehabilitation in supported education services: results of a national survey. Presented at the National Research Seminar on Vocational Rehabilitation and Mental Illness; October 12, 2000; Philadelphia, PA.

5. Pettella C, Tarnoczy DL, Geller D. Supported education: functional techniques for success. Psychiatric Rehabilitation Journal. 1996;20(1):37-41.

6. Cook J, Solomon M. The Community Scholars Program: an outcome study of supported education for students with severe mental illness. Psychosocial Rehabilitation Journal. 1993;16:83-97.

7. Hoffman F, Mastrianni X. The role of supported education in the inpatient treatment of young adults: a two-site comparison. Psychosocial Rehabilitation Journal. 1992;16:109-119.

8. Mowbray CT, Collins ME, Bybee D. Supported education for individuals with psychiatric disabilities: long-term outcomes from an experimental study. Social Work Research. 1999;23(2):89-100.

9. Unger K, Anthony $\mathrm{W}$, Sciarappa $\mathrm{K}$, et al. Supported education program for young adults with long-term mental ilness. Hospital and Community Psychiatry. 1991:42:179.

10. Mowbray CT, Moxley DP, Brown KS. A framework for initiating supported education programs. Psychosocial Rehabilitation Journal. $1993 ; 17: 129-149$.

11. Zander A. Effective Social Action by Community Groups. San Francisco: Jossey-Bass; 1990. 